\title{
Surgery for patients with Marfan syndrome with type A dissection involving the aortic arch using total arch replacement combined with stented elephant trunk implantation: The acute versus the chronic
}

\author{
LiZhong Sun, MD, ${ }^{\mathrm{a}}$ Ming Li, MD, ${ }^{\mathrm{b}}$ JunMing Zhu, MD, ${ }^{\mathrm{a}}$ YongMin Liu, MD, ${ }^{\mathrm{a}}$ Qian Chang, MD, ${ }^{\mathrm{a}}$ \\ Jun Zheng, MD, ${ }^{\mathrm{a}}$ and RuiDong Qi, $\mathrm{MD}^{\mathrm{c}}$
}

\begin{abstract}
Objective: The optimal surgical repair for patients with Marfan syndrome with type A dissection involving the aortic arch is controversial. We retrospectively reviewed our experience of total arch replacement combined with stented elephant trunk implantation for patients with Marfan syndrome with type A dissection.
\end{abstract}

\begin{abstract}
Methods: Between April 2003 and September 2008, 44 patients with Marfan syndrome (acute = 19, chronic $=25$ ) with type A dissection underwent this procedure. Postoperative computed tomography was used to evaluate thrombosis and absorption of the residual false lumen.
\end{abstract}

\begin{abstract}
Results: In-hospital mortality was $4.55 \%(2 / 44)$ (acute $=0 \%, 0 / 19$; chronic $=8.00 \%, 2 / 25)$ and follow-up death rate was $4.76 \%(2 / 42)$ (acute $=5.26 \%, 1 / 19$; chronic $=4.35 \%, 1 / 23)$ during a mean follow-up of 38 \pm 17 months. One patient $(5.26 \%, 1 / 19)$ with chronic dissection underwent thoracoabdominal aortic replacement 7 months after surgery. Injury to the spinal cord and visceral ischemia were not observed during follow-up. Obliteration of the false lumen around the stented elephant trunk was observed in $76.2 \%$ of patients $(32 / 42)($ acute $=84.2 \%, 16 / 19$; chronic $=69.6 \%, 16 / 23)$ as demonstrated by postoperative computed tomography. The distal end of the stent-graft entering the false lumen was observed in 4 patients $(21.1 \%, 4 / 19)$ with acute dissection.

Conclusions: The procedure was a suitable alternative to patients with Marfan syndrome with chronic type A dissection. However, more attention should be paid to patients with Marfan syndrome with acute dissection caused by the fragile dissecting membrane. If this procedure was adopted in patients with Marfan syndrome with acute type A dissection, an entry adjacent to the distal end of the surgical stent-graft, a small true lumen, or an extremely tortuous morphology of the false lumen aorta should be excluded. (J Thorac Cardiovasc Surg 2011;142:e85-91)
\end{abstract}

Marfan syndrome is a genetic disorder of connective tissue. Aortic aneurysms and aortic dissection followed by aortic rupture are the main causes of morbidity and mortality in Marfan syndrome, and surgical treatment is recommended to prevent these severe complications. Because of weakened abnormal aortic tissue, multiple aortic surgeries are required in patients with Marfan syndrome. A high incidence of aneurysmal dilatation of the distal aorta after proximal

\footnotetext{
From the Department of Cardiovascular Surgery, ${ }^{\mathrm{a}}$ Cardiovascular Institute and Fuwai Hospital, Peking Union Medical College, Chinese Academy of Medical Sciences, Beijing, China; the Department of Cardiovascular Surgery, ${ }^{\mathrm{b}}$ People's Hospital of Xinjiang Uygur Autonomous Region, Urumqi, China; and the Department of Cardiovascular Surgery, ${ }^{\mathrm{c}}$ Tianjin Cardiovascular Institute and Tianjin Chest Hospital, Tianjin, China.

Disclosures: Authors have nothing to disclose with regard to commercial support. LiZhong Sun and Ming Li contributed equally to this work.

Drs LiZhong Sun, JunMing Zhu, YongMin Liu, and Jun Zheng are currently at Beijing Aortic Disease Center, Beijing Institute of Heart, Lung and Blood Vessel Diseases and Beijing Anzhen Hospital, Capital Medical University, Beijing, China. Received for publication March 13, 2010; revisions received Dec 7, 2010; accepted for publication Jan 21, 2011; available ahead of print March 7, 2011.

Address for reprints: LiZhong Sun, MD, Beijing Aortic Disease Center, Beijing Anzhen Hospital, Capital Medical University, 2 Anzhen Road, Beijing 100029, China (E-mail: slzh_2005@yahoo.com.cn).

$0022-5223 / \$ 36.00$

Copyright (C) 2011 by The American Association for Thoracic Surgery

doi:10.1016/j.jtcvs.2011.01.038
}

aortic surgery was observed in patients with Marfan syndrome with type A dissection, and a high prevalence of reoperation was observed. ${ }^{1,2}$ To avoid technically challenging procedures after proximal aortic surgery, complete replacement of the aortic arch with an elephant trunk procedure was recommended for patients with Marfan syndrome presenting with type A dissection at the first operation. ${ }^{1}$ Stent-graft repair of descending aortic dissection after previous proximal aortic surgery was also considered to be an alternative to open surgery in these patients. ${ }^{3,4}$ Since 2003, total arch replacement combined with stented elephant trunk implantation has been carried out to treat patients with Marfan syndrome with acute and chronic type A dissection at the Chinese Academy of Medical Sciences in Beijing, China. Preliminary studies have shown that this procedure is feasible for patients with Marfan syndrome with acute type A dissection. ${ }^{5}$ This article presents the outcomes of surgical treatment of acute and chronic type A dissection in patients with Marfan syndrome by using the stented elephant trunk procedure.

\section{PATIENTS AND METHODS}

The procedure described was approved by the institutional review board of the Chinese Academy of Medical Science and Peking Union 


\section{Abbreviations and Acronyms \\ $\mathrm{CPB}=$ cardiopulmonary bypass \\ $\mathrm{CT}=$ computed tomography \\ $\mathrm{SCP}=$ selective cerebral perfusion}

Medical College. Informed consent was obtained from each patient before surgery.

Forty-four patients with Marfan syndrome with type A dissection underwent total arch replacement combined with stented elephant trunk implantation between April 2003 and September 2008. There were 30 male and 14 female patients with a mean age of $37 \pm 10$ years (range, $17-65$ years). Surgery was performed within 2 weeks of the onset of acute aortic dissection in 19 patients and more than 2 weeks after the onset of acute aortic dissection in 25 patients. The diagnosis of Marfan syndrome was based on revised diagnostic criteria. ${ }^{6}$ The clinical profiles of patients with Marfan syndrome with acute and chronic type A dissection undergoing this procedure are listed in Table 1.

The tear site was at the ascending aorta in 26 patients, at the transverse arch in 1 patient, and at the proximal descending thoracic aorta in 4 patients. Multi-tear sites were observed in 9 patients, and previous surgery (Bentall procedure) had been carried out in 4 patients. The dissection extended into the distal descending thoracic aorta in 4 patients, the abdominal aorta in 18 patients, and the iliac artery in 22 patients. All patients with type A dissection underwent total replacement of the aortic arch combined with stented elephant trunk implantation under hypothermic cardiopulmonary bypass (CPB) with selective cerebral perfusion (SCP). Concomitant procedures and intraoperative data are listed in Table 2. Postoperative computed tomography $(\mathrm{CT})$ with contrast enhancement was performed routinely to assess the residual false lumen and the aortic diameter during follow-up.

\section{Surgical Procedure}

The surgical procedure for type A dissection has been described in detail by our research group. ${ }^{5,-10}$ In brief, an intraoperative stent-graft (MicroPort Medical Company Limited, Shanghai, China) ${ }^{5}$ and a 4-branched prosthetic graft (Meadox Hemashield Platinum 4 Branch Graft; Boston Scientific Inc, Boston, Mass) were used. A unilateral SCP technique and the open aortic technique were adopted for total arch replacement. Cannulation of the right axillary artery was routinely carried out for CPB and SCP. This procedure was done in all patients via a median sternotomy under hypothermic CPB with SCP. After the anastomosis between the 4-branched prosthetic graft and the distal aorta containing the intraoperative stentgraft was completed, anastomosis to the left carotid artery was performed. A proximal anastomosis to the 4-branched prosthetic graft was then carried out. Subsequently, reconstructions of the left subclavian artery and the innominate artery were accomplished in succession.

\section{Statistical Analyses}

SPSS version 13.0 (SPSS Inc, Chicago, Ill) was used for analyses. The Student $t$ test was used for continuous variables. Categoric variables were analyzed by the chi-square test or Fisher exact test (as appropriate).

\section{RESULTS}

\section{Surgical Data}

The preoperative risk factors were similar between the 2 groups (Table 1). In patients who underwent concomitant procedures, no differences were found between acute and chronic dissection (Table 2). The CPB and SCP times did not differ between the 2 groups (Table 2). However, the cross- clamp time was significantly shorter in patients with chronic dissection than in those with acute dissection $(P=.001)$.

\section{Morbidity and Mortality}

There were 2 deaths in the chronic group and no inhospital deaths in the acute group $(0 \%$ vs $8 \%$ [2/25], $P=.498$ ). One patient had a new dissection in the abdominal aorta 2 days after surgery. The abdominal aorta manifested 3-channeled aortic dissection. The origin of the celiac artery, superior mesenteric artery, and renal artery was obstructed by the intimal flap. Ischemia in visceral organs was observed. The patient then underwent thoracoabdominal aortic replacement but died of multiple-organ failure caused by irreversible visceral organ ischemia. The other patient had difficulty in ventilatory weaning because of tracheostenoses resulting from tracheomalacia and died of multiple-organ failure 22 days after surgery.

In patients with postoperative morbidity, there was no significant difference between acute and chronic dissection (Table 3). However, postoperative complications were observed more often in the acute group. Cerebral infarction occurred in 1 patient with thrombosis of the innominate artery, 1 patient with low cardiac output, and 1 patient with recurrent laryngeal nerve injury. They all made a good recovery before hospital discharge. A return to the operating room because of bleeding was necessary in 1 of 19 patients $(5.26 \%)$ in the acute group and 1 of 25 patients $(4.00 \%)$ in the chronic group. Paraplegia and visceral ischemia were not observed.

\section{Follow-up}

The follow-up results are shown in Table 3. One patient with acute dissection was lost to follow-up. There was 1 late death in each group during a mean follow-up of $38 \pm$ 17 months (acute $=5.26 \%[1 / 19]$ vs chronic $=4.34 \%$ [1/23], $P=1.000)$. One patient with acute dissection who underwent axillary-axillary artery bypass died of an unknown cause 14 months after surgery. The other patient with chronic dissection had previous ascending aortic replacement and died of severe refractory heart failure 4 months after surgery. One patient with chronic dissection had cerebral infarction and recovered uneventfully. Compared with acute dissection, 1 patient with chronic dissection received thoracoabdominal aortic replacement 7 months after surgery, and discharge from the hospital was uneventful. Injury to the spinal cord and visceral ischemia were not observed during follow-up.

\section{Imaging}

Obliteration of the false lumen around the stented elephant trunk was observed in $76.2 \%$ of patients $(32 / 42)$ (acute $=84.2 \%[16 / 19]$ vs chronic $=69.6 \%$ [16/23], $P=.305$ ), and complete thrombus formation at the diaphragmatic level occurred in $45.2 \%$ of patients (19/42) 
TABLE 1. Clinical profiles of patients with Marfan syndrome with acute and chronic type $A$ dissection

\begin{tabular}{lcccr}
\hline \multicolumn{1}{c}{ Variable } & Acute & & Chronic & \\
\cline { 2 - 2 } & $\mathbf{n = 1 9}$ & & $\mathbf{n = 2 5}$ & $\boldsymbol{P}$ value \\
\hline Age (y \pm SD) & $37 \pm 13$ & $37 \pm 8$ & .935 \\
Male, n (\%) & $16(84.2)$ & $14(56.0)$ & .058 \\
Female, n (\%) & $3(15.8)$ & $11(44.0)$ & .058 \\
Hypertension, n (\%) & $7(36.8)$ & $7(28.0)$ & .533 \\
Acute left heart failure, n (\%) & $2(10.5)$ & $0(0)$ & .181 \\
Coronary heart disease, n (\%) & $0(0)$ & $1(4.0)$ & 1.000 \\
Lower-extremity ischemia, n (\%) & $1(5.3)$ & $1(4.0)$ & 1.000 \\
Cerebral embolism, n (\%) & $0(0)$ & $1(4.0)$ & 1.000 \\
Chronic renal dysfunction, n (\%) & $1(5.3)$ & $1(4.0)$ & 1.000 \\
Pulmonary infection, n $(\%)$ & $1(5.3)$ & $0(0)$ & .432 \\
\hline
\end{tabular}

$S D$, Standard deviation.

(acute $=57.9 \%$ [11/19] vs chronic $=34.8 \%$ [8/23], $P=.134)$ as demonstrated by postoperative CT (Figure 1). Obliteration of the false lumen around the upper middle portion of the stented elephant trunk was observed in $17.4 \%$ of patients $(4 / 23)$ with chronic dissection. The speed of thrombus formation in the false lumen was low in patients with Marfan syndrome, as demonstrated by postoperative CT (Figure 1). Enlargement of the diameter of the descending aorta was observed in 3 patients with acute dissection $(5.11 \pm 0.48 \mathrm{~cm}$ vs $3.89 \pm 0.92 \mathrm{~cm}$ preoperatively) and in 6 patients with chronic dissection postoperatively $(4.99 \pm 0.88 \mathrm{~cm}$ vs $4.03 \pm 0.62 \mathrm{~cm}$ preoperatively) $(P=.714)$.

Although there were no differences between the 2 groups in patients with imaging data, the distal end of the stentgraft entered the false lumen in 4 patients with acute dissection $(21.1 \%, 4 / 19)$. Entry adjacent to the distal end of the stent-graft was observed in 3 patients with acute dissection (Figure 2), and the tortuous morphology of the false lumen

TABLE 2. Concomitant procedures and intraoperative data

\begin{tabular}{|c|c|c|c|}
\hline & Acute & Chronic & \\
\hline Variable & $\mathbf{n}=\mathbf{1 9}$ & $\mathbf{n}=\mathbf{2 5}$ & $P$ value \\
\hline Bentall procedure, $\mathrm{n}(\%)$ & $17(89.5)$ & $16(64)$ & .081 \\
\hline Aortic valve plasty, n (\%) & $1(5.3)$ & $0(0)$ & .432 \\
\hline Aortic valve replacement, $\mathrm{n}(\%)$ & $1(5.3)$ & $0(0)$ & .432 \\
\hline Mitral valve replacement, n (\%) & $0(0)$ & $1(4.0)$ & 1.000 \\
\hline David procedure, $\mathrm{n}(\%)$ & $0(0)$ & $1(4.0)$ & 1.000 \\
\hline Coronary artery bypass graft, $\mathrm{n}(\%)$ & $1(5.3)$ & $1(4.0)$ & 1.000 \\
\hline Axillary-axillary artery bypass, $\mathrm{n}(\%)$ & $1(5.3)$ & $0(0)$ & .432 \\
\hline $\begin{array}{l}\text { Ascending aorta-femoral artery } \\
\text { bypass, } \mathrm{n}(\%)\end{array}$ & $0(0)$ & $1(4.0)$ & 1.000 \\
\hline Femoral-femoral artery bypass, $\mathrm{n}(\%)$ & $0(0)$ & $1(4.0)$ & 1.000 \\
\hline $\mathrm{CPB}$ time $(\min \pm \mathrm{SD})$ & $193 \pm 39$ & $176 \pm 27$ & .165 \\
\hline Crossclamp time $(\min \pm \mathrm{SD})$ & $124 \pm 26$ & $100 \pm 19$ & .001 \\
\hline SCP time $(\min \pm \mathrm{SD})$ & $27 \pm 14$ & $22 \pm 5$ & .161 \\
\hline
\end{tabular}

TABLE 3. Postoperative and follow-up results

\begin{tabular}{|c|c|c|c|}
\hline & Acute & Chronic & $\boldsymbol{P}$ \\
\hline Variable & $\mathbf{n}=19$ & $\mathbf{n}=\mathbf{2 5}$ & \\
\hline Cerebral infarction & $1(5.3)$ & $0(0)$ & .432 \\
\hline Left upper-limb ischemia & $1(5.3)$ & $0(0)$ & .432 \\
\hline Injury to recurrent nerves, $\mathrm{n}(\%)$ & $1(5.3)$ & $0(0)$ & .432 \\
\hline Low cardiac output & $1(5.3)$ & $0(0)$ & .432 \\
\hline $\begin{array}{l}\text { Return to operating room for } \\
\text { bleeding, } \mathrm{n}(\%)\end{array}$ & $1(5.3)$ & $1(4.0)$ & 1.00 \\
\hline In-hospital death, n (\%) & $0(0)$ & $2(8.0)$ & .49 \\
\hline Follow-up time $(\mathrm{mo} \pm \mathrm{SD})$ & $38 \pm 17$ & $38 \pm 18$ & .99 \\
\hline Lost to follow-up, n (\%) & $1(5.3)$ & $0(0)$ & .43 \\
\hline $\begin{array}{l}\text { Thoracoabdominal aortic replacement, } \\
\mathrm{n}(\%)\end{array}$ & $0(0)$ & $1(4.0)$ & 1.00 \\
\hline Follow-up death, n (\%) & $1(5.3)$ & $1(4.0)$ & 1.00 \\
\hline
\end{tabular}

$S D$, Standard deviation.

was demonstrated by preoperative CT in 1 patient. Preoperative CT also showed a small true lumen of the descending aorta being compressed by a large false lumen (Figure 2). One possible explanation might be that the intimal layer was lacerated along the preoperative entry after the surgical stent spread into the small true lumen of the distal aorta because of the fragile aortic wall in patients with Marfan syndrome. Because of the extremely tortuous morphology of the false lumen, the intimal layer might be torn during implantation of the stented elephant trunk. Shrinkage of the descending aorta was observed in 3 of 4 patients during follow-up.

\section{DISCUSSION}

After introduction of the Bentall composite graft procedure, aortic root replacement was the standard procedure for patients with Marfan syndrome with aortic root lesions. ${ }^{11}$ Low surgical mortality and excellent long-time results were achieved. ${ }^{12,13}$ In patients with Marfan syndrome with acute ${ }^{1,14,15}$ and chronic ${ }^{15}$ type A dissection after successful aortic root replacement, the distal dissected aorta remained a source of late complications. Aortic dissection during the initial surgical procedure was identified as the only significant risk factor for distal aortic reoperations. The rate of reoperation was significantly higher in patients with residual dissection than in patients without residual dissection. ${ }^{15}$ Concomitant total replacement of the transverse arch has been recommended for patients with Marfan syndrome with acute ${ }^{1,14,15}$ and chronic ${ }^{15}$ type A aortic dissection involving the aortic arch during the initial procedure because of a high rate of reoperation, although this is not recommended in patients with Marfan syndrome without aortic dissection. Patients with Marfan syndrome tend to be younger and to survive longer after the initial successful surgery. In a staged operation for entire aortic replacement, concomitant total arch replacement was more advantageous than aortic root replacement alone. ${ }^{15}$ Concomitant total 


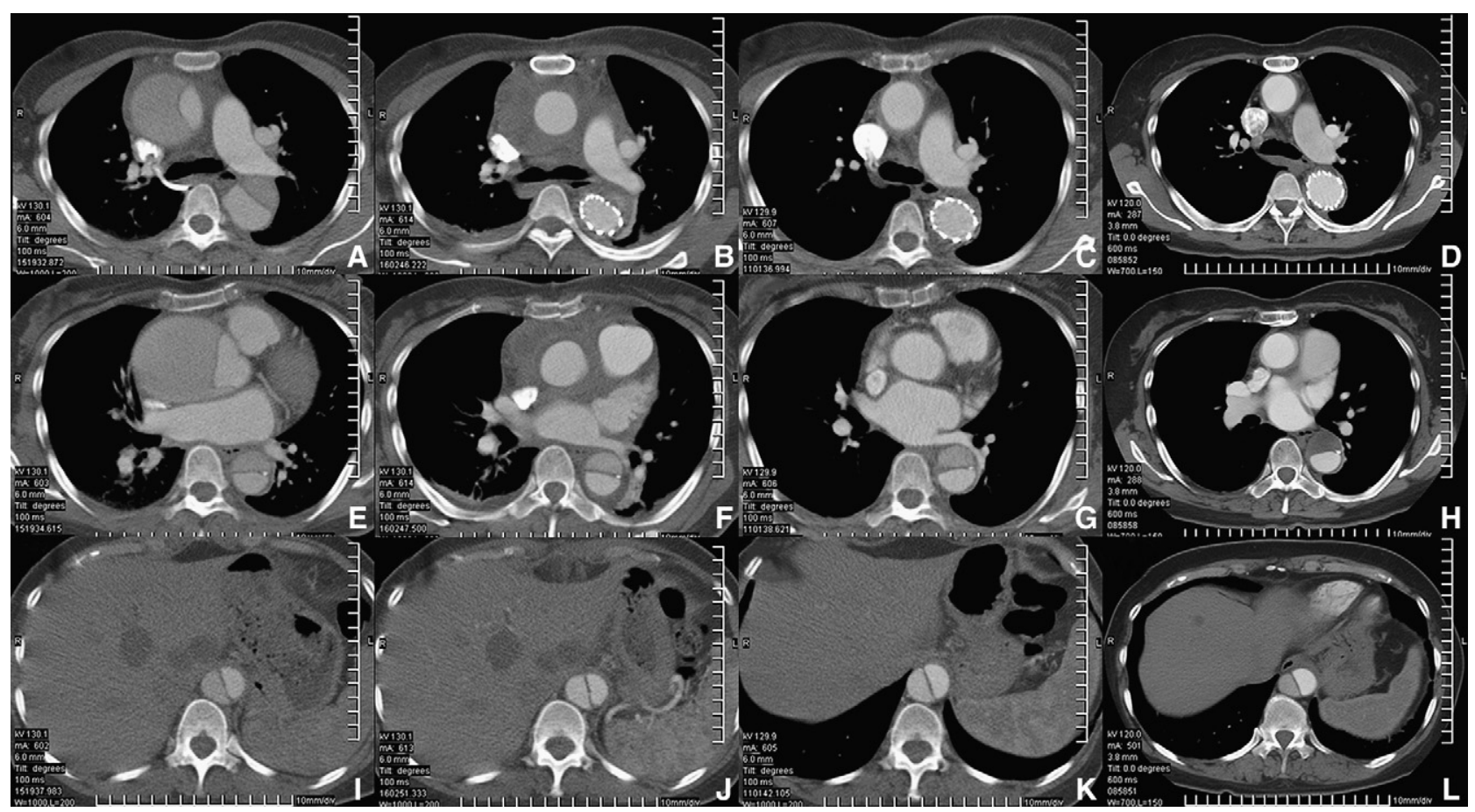

FIGURE 1. CT scan of a patient with chronic type A dissection before surgery (A, E, I) and 2 weeks (B, F, G), 6 months (C, G, K), and 13 months (D, H, L) after surgery. Thrombosis of the false lumen was observed 2 weeks after surgery (B), and thrombosis of the false lumen was reabsorbed gradually after aortic wall remodeling around the stented elephant trunk (B, C, D). The false lumen was obliterated with thrombosis distal to the surgical stent-graft 30 months postoperatively $(\mathrm{H})$; the false lumen with blood flow decreased gradually, and lower thrombus absorption of the false lumen in the descending aorta was observed from 2 to 30 weeks (J, K, L).

arch replacement might be justified for patients with Marfan syndrome with acute and chronic type A dissection. However, significant differences in the rate of reoperation were not found between patients with Marfan syndrome with and without concomitant total arch replacement, which may be correlated to the persistent patent false lumen in the dissected descending aorta. ${ }^{15}$ To avoid repeat sternotomy and facilitate late distal aortic reintervention, total arch replacement with an elephant trunk procedure is recommended. Because of the advantages of favorable intraoperative manipulation and good postoperative recovery, a stented elephant trunk was implanted into the distal aorta during the replacement of the total arch in our patients.

Endovascular stent-graft treatment is a possible alternative to open reoperation after previous successful proximal aortic surgery. ${ }^{3,4,16}$ Because fixation zones for endografts are prone to dilatation, the rate of primary and secondary endoleaks is high in patients with Marfan syndrome. ${ }^{17}$ The aorta continues to dilate despite graft deployment and false lumen thrombosis in patients with Marfan syndrome. ${ }^{4}$ Conversion to open surgery is required in most patients undergoing endovascular stent-graft treatment. ${ }^{16,17}$ Endovascular stent-graft treatment is considered a "bridging" rather than a curative procedure. ${ }^{18}$ Managing stentgraft failure is an intractable problem because the need to remove a failed endograft increases the complexity of the aortic reconstruction, constitutes a large surgical trauma, and requires an extensive protocol. ${ }^{19,20}$ Endografting distal aortic lesions is not a viable option for patients with Marfan syndrome because of their extensive and aggressive aortopathy. ${ }^{20}$

Total replacement of the arch with an elephant trunk has been recommended in patients with Marfan syndrome with type A dissection during the initial procedure, ${ }^{1}$ but placing the conventional elephant trunk in the true lumen in patients with Marfan syndrome is difficult. The aortic wall of patients with Marfan syndrome is weak and fragile, and the true lumen is compressed by the false lumen. Complications have been observed using the conventional elephant trunk procedure, ${ }^{21}$ including kinking and obstruction of the graft, embolization, and paraplegia. Selecting an appropriate interval between the first and the second stages of the procedure using the conventional elephant trunk is also difficult. $^{22}$ Rupture of the nonoperated aortic segment has occurred between the 2 procedures; deaths were recorded. ${ }^{23}$ Shortening the recovery period increases the risk associated with the second stage of the procedure. Furthermore, some patients fail to return for the second-stage procedure. ${ }^{23}$

In view of the limitations of the stent-graft procedure, the stented elephant trunk procedure can be used to treat Marfan syndrome, as demonstrated by Sun and colleagues. ${ }^{5}$ The outstanding advantage of this procedure is that 


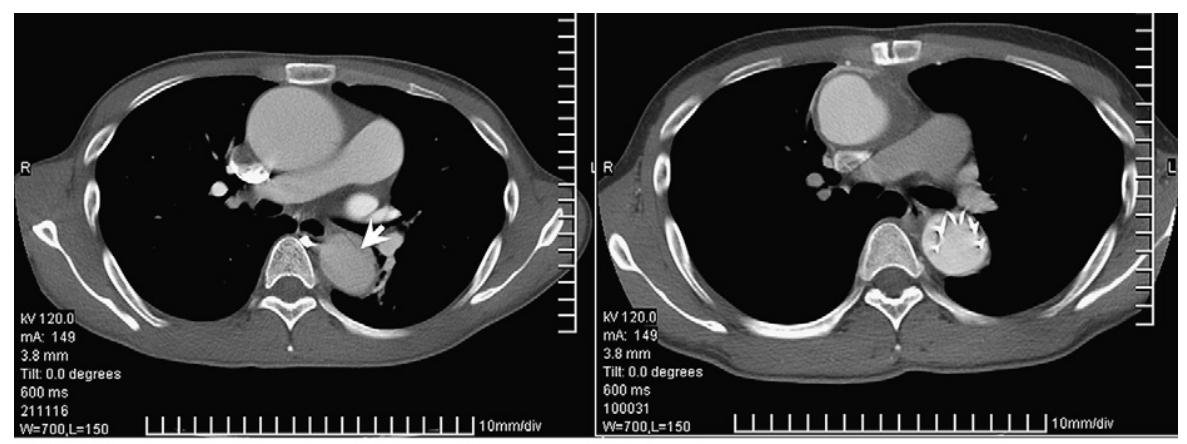

A

B

FIGURE 2. CT scan of a patient with Marfan syndrome with acute type A dissection before (A) and 2 weeks after (B) surgery. A small true lumen of the descending aorta is compressed by a large false lumen. A large gap is present between the false and true lumens (A). The distal end of the surgical stent-graft entered the false lumen.

attachment to the aortic wall of the stented elephant trunk can be achieved by the suture line, not by the radial force of the stent-graft, in patients undergoing endovascular stent-graft treatment. This has 2 advantages. First, appropriate sizing of the stented elephant trunk is close to the diameter of the proximal descending aorta of normal subjects matched for age, sex, and height, and similar to the physical state of the aorta. Injury to the aortic wall caused by the radial force of the stented elephant trunk is small. New dissection is probably related to excessive oversizing of the endograft with respect to the aortic diameter. ${ }^{3}$ Second, the stent binds the sutures more solidly between the stented elephant trunk and the aortic wall, reducing the risk of dangerous endoleaks. The surgical stented elephant trunk also has the characteristics of endovascular stent-graft treatment and promotes thrombosis of the false lumen. In the current study, obliteration of the false lumen around the stented elephant trunk was observed in $76.2 \%$ of patients $(32 / 42)$ (acute, 84.2\% [16/19] vs chronic, 69.6\% [16/23]) and complete thrombus formation at the diaphragmatic level occurred in $45.2 \%(19 / 42)$ of patients (acute, 57.9\% [11/19] vs chronic, $34.8 \%$ [8/23]) as shown by postoperative CT. If late thoracoabdominal aortic replacement was required, thoracoabdominal aortic replacements were implemented because the distal end of the surgical stent-graft had $1 \mathrm{~cm}$ of extra vascular graft that was used for sewing. This also simplified the secondary procedure. In this group, 4 patients with previous aortic root replacement successfully underwent this procedure.

The stented elephant trunk procedure was modified according to the shortcomings of the conventional elephant trunk procedure. Its main advantages were good intraoperative handling and postoperative recovery. Several intractable problems with intraoperative manipulation in the conventional elephant trunk procedure were resolved using this procedure. First, it was easy to apply the stent elephant trunk in a bound, compressed state into the descending aorta under direct vision. This decreased the injury to the weak and fragile aortic wall of patients with Marfan syndrome. Second, this procedure enlarged the true lumen and ameliorated organ ischemia. Third, this procedure conferred protection against rupture and prolonged the reoperation interval. Because the intimal tear in the proximal descending aorta was sealed off by the stented elephant trunk, the distal aortic arch was transected between the origin of the left subclavian artery and the left common carotid artery. This simplified total arch replacement, reduced the risk of injury to the recurrent laryngeal nerve, and avoided the difficulty in carrying out the distal anastomosis. Stabilization of the distal aortic arch and proximal descending aorta was achieved after the resection of the entire native arch tissue and implantation of the stented elephant trunk. In postoperative recovery, this procedure had advantages over the conventional elephant trunk procedure. This procedure prevented complications, such as kinking and obstruction of the graft, and embolization, all of which can be observed in surgery using the conventional elephant trunk. The tear was sealed off where the surgical-graft reached after the stented elephant trunk was implanted into the distal aorta. This benefited thrombus formation in the distal aorta and thus stabilized the distal aorta. Only 1 patient underwent late thoracoabdominal aortic replacement, and no aortic rupture was observed in this group during a follow-up of $38 \pm 17$ months. This may be attributed to successful exclusion of the false lumen, promotion of thrombosis, and shrinkage of the entire aorta.

Two patients with Marfan syndrome with chronic dissection died, but not as a result of the procedure. Organ ischemia from the false lumen was another important factor in patients with Marfan syndrome with chronic type A dissection undergoing this procedure. Our recent work demonstrated the feasibility of this procedure in patients with chronic dissection. ${ }^{10}$ Marfan syndrome is associated with slow formation of clots after stent-graft implantation. This promotes adequate formation of the collateral circulation of the spinal cord during the slow thrombosis of the false 
lumen after implantation of the stented elephant trunk. This was also confirmed by the fact that injury to the spinal cord was not observed in this group.

Encouraging operative outcomes have been obtained in patients with acute and chronic type A dissection using total arch replacement combined with stented elephant trunk implantation. ${ }^{7,8,10}$ Because of the relatively rigid chronic dissected membrane, implantation of the stented elephant trunk into the distal aorta was feasible if aortic dissection extended beyond the aortic arch, as illustrated by our imaging data. The stented elephant trunk procedure was a good indication for patients with Marfan syndrome with chronic type A dissection involving the aortic arch. However, the surgical stent was seen to enter the false lumen in 4 patients with acute dissection undergoing the stented elephant trunk procedure because of the weakness and fragility of the dissecting membrane. More attention should be paid to patients with Marfan syndrome with acute dissection when using this technique.

It is debatable whether patients with Marfan syndrome with aortic dissection benefit from the stented elephant trunk procedure. After implantation of the stented elephant trunk into the distal aorta, the intimal tear in the descending aorta where the stented elephant trunk could reach was sealed off, decreasing the pressure of the false lumen. Thrombosis of the false lumen occurred with exclusion of the large tear distal to the end of the surgical stent or endoleak. Thrombus formation in the false lumen reduced stress in the aortic wall, preventing subsequent growth of the distal aorta. Because of the weakness and fragility of the aortic wall, dilatation of the distal aorta was observed in some patients. As also described in a recent report, ${ }^{4}$ the aorta continued to dilate despite coverage of the primary tear and thrombosis of the false lumen. Second-stage surgery is essential in some patients undergoing this procedure because of aneurysm dilatation of the distal aorta. In comparison with the classic elephant trunk, late distal aortic surgery using the stented elephant trunk procedure is easy and technically feasible. ${ }^{24}$ Although the surgical stent was seen to enter the false lumen in 4 patients, shrinkage of the descending aorta was observed in 3 of 4 patients during follow-up. The true lumen exists in the downstream aorta distal to the end of the surgical stent. Both lumens (true and false) were perfused. This resembles the situation when a portion of the septum between the true and false lumen is excised to permit perfusion of both channels. In addition, we thought this severe complication could be decreased after careful assessment and exclusion. Because of the abnormally fragile tissue of the aortic wall during the acute stage, it is vital to select patients with Marfan syndrome without a preoperative entry adjacent to the distal end of the surgical stent-graft, a small false lumen of the proximal descending aorta, or extremely tortuous morphology of the false lumen. Also, shortening or lengthening the surgical stent-graft to lengthen the distance between the intimal tear and the distal end of the surgical stent-graft (10 cm long) may be an option.

\section{CONCLUSIONS}

The procedure described is feasible in patients with Marfan syndrome with type A dissection involving the aortic arch and is a good choice for patients with Marfan syndrome with chronic type A dissection because of the rigid chronic dissecting membrane. However, more attention should be paid to patients with Marfan syndrome with acute dissection. Because of the abnormally fragile tissue of the aortic wall during the acute stage, it is vital to select patients with Marfan syndrome without a preoperative entry adjacent to the distal end of the surgical stent-graft, a small false lumen of the proximal descending aorta, or extremely tortuous morphology of the false lumen. Careful, gentle manipulation to reduce injury to the aortic wall is also crucial. Close long-term follow-up is required to validate the effectiveness of this procedure for patients with Marfan syndrome.

\section{References}

1. Girdauskas E, Kuntze T, Borger MA, Falk V, Mohr FW. Distal aortic reinterventions after root surgery in Marfan patients. Ann Thorac Surg. 2008;86:1815-9.

2. Bachet JE, Termignon JL, Dreyfus G, Goudot B, Martinelli L, Piquois A, et al. Aortic dissection. Prevalence, cause, and results of late reoperations. J Thorac Cardiovasc Surg. 1994;108:199-206.

3. Botta L, Russo V, La Palombara C, Rosati M, Di Bartolomeo R, Fattori R. Stent graft repair of descending aortic dissection in patients with Marfan syndrome: an effective alternative to open reoperation? J Thorac Cardiovasc Surg. 2009;138:1108-14.

4. Nordon IM, Hinchliffe RJ, Holt PJ, Morgan R, Jahangiri M, Loftus IM, et al. Endovascular management of chronic aortic dissection in patients with Marfan syndrome. J Vasc Surg. 2009;50:987-91.

5. Sun LZ, Qi RD, Chang Q, Zhu JM, Liu YM, Yu CT, et al. Surgery for Marfan patients with acute type A dissection using a stented elephant trunk procedure. Ann Thorac Surg. 2008;86:1821-5.

6. De Paepe A, Devereux RB, Dietz HC, Hennekam RC, Pyeritz RE. Revised diagnostic criteria for the Marfan syndrome. Am J Med Genet. 1996;62:417-26.

7. Liu ZG, Sun LZ, Chang Q, Zhu JM, Dong C, Yu CT, et al. Should the "elephant trunk" be skeletonized? Total arch replacement combined with stented elephant trunk implantation for Stanford type A aortic dissection. J Thorac Cardiovasc Surg. 2006;131:107-13.

8. Sun LZ, Qi RD, Chang Q, Zhu JM, Liu YM, Yu CT, et al. Surgery for acute type A dissection using total arch replacement combined with stented elephant trunk implantation: Experience with 107 patients. J Thorac Cardiovasc Surg. 2009; 138:1358-62.

9. Sun LZ, Qi RD, Chang Q, Zhu JM, Liu YM, Yu CT, et al. Surgery for acute type A dissection with the tear in the descending aorta using a stented elephant trunk procedure. Ann Thorac Surg. 2009;87:1177-80.

10. Sun LZ, Qi RD, Chang Q, Zhu JM, Liu YM, Yu CT, et al. Is total arch replacement combined with stented elephant trunk implantation justified for patients with chronic Stanford type A aortic dissection? J Thorac Cardiovasc Surg. 2009;138:892-6.

11. Bentall H, De Bono A. A technique for complete replacement of the ascending aorta. Thorax. 1968;23:338-9.

12. Cameron DE, Alejo DE, Patel ND, Nwakanma LU, Weiss ES, Vricella LA, et al. Aortic root replacement in 372 Marfan patients: evolution of operative repair over 30 years. Ann Thorac Surg. 2009;87:1344-50.

13. Gott VL, Greene PS, Alejo DE, Cameron DE, Naftel DC, Miller DC, et al. Replacement of the aortic root in patients with Marfan's syndrome. $N$ Engl J Med. 1999;340:1307-13.

14. Bachet J, Larrazet F, Goudot B, Dreyfus G, Folliguet T, Laborde F, et al. When should the aortic arch be replaced in Marfan patients? Ann Thorac Surg. 2007;83: S774-9. 
15. Tagusari O, Ogino H, Kobayashi J, Bando K, Minatoya K, Sasaki H, et al. Should the transverse aortic arch be replaced simultaneously with aortic root replacement for annuloaortic ectasia in Marfan syndrome? J Thorac Cardiovasc Surg. 2004; $127: 1373-80$.

16. Ince H, Rehders TC, Petzsch M, Kische S, Nienaber CA. Stent-grafts in patients with Marfan syndrome. J Endovasc Ther. 2005;12:82-8.

17. Marcheix B, Rousseau H, Bongard V, Heijmen RH, Nienaber CA, Ehrlich M, et al. Stent grafting of dissected descending aorta in patients with Marfan's syndrome mid-term results. JACC Cardiovasc Interv. 2008;1: 673-80.

18. Akin I, Kische S, Rehders TC, Chatterjee T, Schneider H, Korber T, et al. Current role of endovascular therapy in Marfan patients with previous aortic surgery. Vasc Health Risk Manag. 2008;4:59-66.

19. Langer S, Mommertz G, Koeppel TA, Schurink GW, Autschbach R, Jacobs MJ. Surgical correction of failed thoracic endovascular aortic repair. J Vasc Surg. 2008;47:1195-202.
20. LeMaire SA, Carter SA, Volguina IV, Laux AT, Milewicz DM, Borsato GW, et al Spectrum of aortic operations in 300 patients with confirmed or suspected Marfan syndrome. Ann Thorac Surg. 2006;81:2063-78.

21. Crawford ES, Coselli JS, Svensson LG, Safi HJ, Hess KR. Diffuse aneurysmal disease (chronic aortic dissection, Marfan, and mega aorta syndromes) and multiple aneurysm. Treatment by subtotal and total aortic replacement emphasizing the elephant trunk operation. Ann Surg. 1990;211:521-37.

22. LeMaire SA, Carter SA, Coselli JS. The elephant trunk technique for staged repair of complex aneurysms of the entire thoracic aorta. Ann Thorac Surg. 2006 81:1561-9.

23. Safi HJ, Miller CC III, Estrera AL, Huynh TT, Rubenstein FS, Subramaniam MH et al. Staged repair of extensive aortic aneurysms: morbidity and mortality in the elephant trunk technique. Circulation. 2001;104:2938-42

24. Pichlmaier MA, Teebken OE, Khaladj N, Weidemann J, Galanski M, Haverich A. Distal aortic surgery following arch replacement with a frozen elephant trunk. Eur J Cardiothorac Surg. 2008;34:600-4.

\title{
COMMENTARY
}

\section{The can-should problem}

\author{
Thoralf M. Sundt III, MD
}

For as this ought, or ought not, expresses some new relation or affirmation, 'tis necessary that it should be observed and explained; and at the same time that a reason should be given ... how this new relation can be a deduction from others, which are entirely different from it.

David Hume, A Treatise of Human Nature, 1739

The place of endovascular stent grafting in the treatment of Marfan syndrome remains unclear; for that matter, so is the place of endovascular stent grafting in acute dissection. Accordingly, the data presented in this study are of interest to the cardiovascular surgical community. Despite "expert consensus" that stent grafts should not be used in patients with connective tissue disorders, we are all seeing more patients in whom they have been used either in ignorance of the underlying condition or in emergency salvage conditions. The morbidity associated with descending thoracic and thoracoabdominal aortic aneurysm disease occurring as a late sequela of dissection is driving application of the "frozen elephant trunk" operation. These authors have ex-

\footnotetext{
From the Division of Cardiac Surgery, Massachusetts General Hospital, Boston, Mass.

Address for reprints: Thoralf M. Sundt III, MD, Edward D. Churchill Professor and Chair, Division of Cardiac Surgery, Massachusetts General Hospital, 55 Fruit St, Boston, MA 02114 (E-mail: tsundt@partners.org).

J Thorac Cardiovasc Surg 2011;142:e91

$0022-5223 / \$ 36.00$

Copyright (c) 2011 by The American Association for Thoracic Surgery

doi:10.1016/j.jtcvs.2011.04.002
}

plored both and conclude "that this procedure is feasible." The question, of course, is whether it is advisable.

The authors have followed 44 Marfan patients with acute $(n=19)$ or chronic $(n=25)$ dissection. Short-term results were acceptable; importantly, there were no instances of paraplegia. Follow-up, however, was only $38 \pm 17$ months. During this period there were 2 deaths and 1 patient required thoracoabdominal aortic replacement. Computed tomographic scanning demonstrated thrombosis around the stent graft, but below that level in only $45 \%$. Furthermore, aortic enlargement - the result of true interest-occurred in 3 of the 19 patients with acute dissection and 6 of the surviving 23 patients with chronic dissection. The stent graft extended into the false lumen in 4 of those with acute dissection. The question is, then, is this success?

One runs the risk of appearing a Luddite when criticizing the use of novel technology. And, of course, it is always more comfortable to sit in the camp of conventional wisdom while another has the courage to challenge dogma. It is not my aim to impune the authors' efforts to advance the treatment of this challenging group of patients. We do, however, need to draw a distinction between therapy that should be considered "experimental" and most appropriate in the setting of a carefully monitored prospective study, and a new standard of care. What is apparent is that we can perform this procedure. What remains unknown is whether we should. 